\title{
Aplikasi Pencarian dan Pembelajaran Hadist Pada Kitab Riyadhus Shalihin Berbasis Mobile
}

\author{
Anik Sri Wahyuningsih \\ Sekolah Tinggi Manajemen Informatika dan \\ Komputer Cikarang \\ Jl. Kapten Sumantri No. 16 Cikarang \\ Indonesia \\ anik_naufal@yahoo.com
}

\author{
Dudi Nurdiana \\ Sekolah Tinggi Manajemen Informatika dan \\ Komputer Cikarang \\ J1. Kapten Sumantri No. 16 Cikarang \\ Indonesia \\ dudi_nurdiana@yahoo.com
}

\begin{abstract}
Hadith is one way of life of Muslims after the Qur'an. Law - Islamic law regulated in the hadith as a law that strengthens the holy verses of the Qur'an. In the hadith contains sayings of the Prophet are then recorded, so many Muslims who are looking for basic - the legal basis based on the hadith is used as a legal basis. To petrified and support the learning we need a system that can search hadith application in accordance with the needs of knowledge, basic law and learning. The purpose of the study authors is to build a search system and hadith with mobile-based learning. It is expected that the application is made the author a reference to improve the deeds of Muslims and ketaqwaanya hello to Allah.
\end{abstract}

Keywords-Hadith, Mobile, Applications, Learning

\section{PENDAHULUAN}

Hadist adalah merupakan pedoman pokok dalam islam disamping Al-quran. Kitab Riyadhus Shalihin adalah salah satu diantara sekian banyak hadits yang membicarakan masalah Aqidah, Syariah dan Akhlak. Yang ketiga-tiganya merupakan sendi ajaran islam. Kitab Riyadhus Shalihin adalah sebuah kitab yang sangat masyur dalam dunia islam. Kitab ini telah dijadikan pegangan selama ratusan tahun bagi para ulama, untuk pembelajaran dan menuntut ilmu Agama Islam dibelahan dunia. Dan pengarang Kitab Riyadhus Shalihin beliau bernama Yahya ibn Syaraf ibn Murri ibn Hasusein ibn Muhamad ibn Jum'at ibn Hizam dan beliau dikenal dengan Abu Zakaria. Dan hampir seluruh isi Kitab Riyadhus Shalihin berisi ruh akan dorongan menghambakan diri kepada Allah serta memupuk amal soleh, dan mayoritas isi dari Hadits Riyadhus Shalihin, diantaranya mengenai masalah hati dan kebersihan jiwa. Pada bagian berikutnya beliau menekankan pada masalah Mu'amalat Mu'asyarah, yakni masalah-masalah yang berhubungan kehidupan manusia bermasyarakat sebagai mahkluk sosial, masalah moral dan adab.

Seiiring dengan berkembangnya ilmu pengetahuan dan teknologi, maka aplikasi berbasis Mobile semakin berkembang juga. Perkembangan tehnologi salah satu yang sangat penting yang harus di ikuti oleh manusia, misalnya handphone yang semula hanya media komunikasi sekarang mempunyai fungsi dasar bisa lebih banyak, serta berbagai macam picture sudah bisa dirasakan diberbagai handphone diantaranya : Video, Camera, Document, dan lain sebagainya. Layaknya komputer handphone saat ini dapat di install dengan berbagai macam program. Dan yang sangat diminati saat ini adalah program aplikasi berbasis android. Android sendiri mempunyai tujuan utama untuk memajukan inovasi piranti handphone bergerak agar pengguna mampu mengeksplorasi kemampuan dan menambah pengalaman lebih dari para pesaingnya dari segi sistem, maupun aplikasinya.

Pemasalahan yang ada pada saat bagi masyarakat luas kurang memahami isi dan makna dari hadits, alasannya karena dalam mencari informasi dan isi dari makna hadits kebanyakan masyarakat umumnya lebih banyak mengakses dengan media kertas. Sistem pencarian dari media kertas lebih banyak memakan waktu cukup lama dan untuk suatu permasalahan harus membuka secara perlembar. Dengan didukungnya oleh para pengembang sistem operasi pada mobile khususnya android. Masalah bagi masyarakat umum tidak perlu repot membuka buku sebagai panduan pengetahuan pembelajaran tentang hadits. Cukup dengan membuka telepon genggam kita bisa meningkatkan pengetahuan dan pembelajaran isi dari makna hadits. Aplikasi ini bertujuan untuk mempermudah setiap orang yang ingin belajar isi dari makna hadits, yang tidak perlu membawa buku hanya cukup dengan menginstal aplikasi di handphone yang sistem operasinya berbasis Android. Aplikasi ini memiliki cara kerja yang 
mudah dipahami, dengan tampilan aplikasi yang sangat menarik, dan dapat digunakan oleh semua kalangan, dengan standar pada handphone berbasis android yang mempunyai layar touch screen, aplikasi ini bisa diakses dengan sentuhan jari pada layar. Dan juga bertujuan untuk mempermudah pembelajaran, dan pengetahuan diberbagai kalangan umat Islam khususnya di Indonesia yang menggunakan piranti mobile berbasis android.

\section{TINJAUAN PUSTAKA}

\section{A. Penelitian Terdahulu}

Dalam penelititian terdahulu yang sudah membuat pengembangan aplikasi pembelajaran diantaranya :

- Pada penelitian lain [1] Membangun Website Indeks Hadits Riyadhus Shalihin Untuk Pengguna Buta Hurup Arab. Website berisi dengan index hadist dalam bentuk huruf arab, huruf latin dan audio. Sehingga dapat mempermudah para pengguna untuk memilih metode yang sesuai baik membaca atau mendengarkan.

- Pada penelitian [2] Membahas penerapan pencarian kata dengan Vector Space Model pada aplikasi terjemahan Juz Amma berbasis Java Mobile. Hasil penelitian ini adalah mempermudah pengguna dalam mempelajari Juz Amma dan hasil pencarian kata yang tepat dan cepat sesuai kata yang diinput.

- Pada penelitian lain [3] Membahas Pembuatan Aplikasi Kitab Fadilah Amal oleh Syakhul Hadits Maulana Muhamad Zakaria Al- Kandahlawi Rah. A Berbasis Android. Pada penelitian ini tampilan menunya praktis sehingga mudah digunakan oleh pengguna.

Masing - masing aplikasi yang sudah dibuat dan dirancang khusus supaya mempermudah user dalam pembelajaran Agama berbasis Mobile. Dengan memanfaatkan tampilan yang simpel dan mudah dimengerti. Penulis ingin membuat aplikasi pembelajaran yang lebih mudah dan menyenangkan. Penulis menggunaka softwareEclipse dengan versi Android 4.0 Jelly Bean karena versi Android inilah yang sering banyak digunakan sebagai standar sistem oprasi mereka. Terdapat perubahan yang cukup segnifikan dari versi sebelumnya. Diantaranya adalah kerangka aplikasi memungkinkan penggunaan dan penghapusan komponen yang tersedia, Delvik Virtual Machine (DVM) yang dioptimalkan untuk perangkat mobile, grafik di 2D dan 3D berdasarkan libraries OpenGL, SQLite, mendukung berbagai format Audio dan Video, GSM, Bloetooth, EDGE, 3G, Wifi, Kamera, Global Posotioning System (GPS) kompas dan Accelerometer's.

\section{B. Aplikasi Mobile}

Aplikasi mobile merupakan aplikasi yang dapat digunakan walaupun pengguna berpindah dengan mudah dari satu tempat ketempat lain lain tanpa terputusnya komunikasi. Aplikasi mobile adalah sebutan untuk aplikasi yang berjalan di mobile device. Dengan menggunakan aplikasi mobile, dapat dengan mudah melakukan berbagai macam aktifitas mulai dari hiburan, berjualan, belajar, mengerjakan pekerjaan kantor, browsing dan lain sebagainya". Aplikasi yang melibatkan piranti bergerak dan melibatkan media komunikasi nirkabel. Oleh karena itu, peminatan ini menekuni sistem tersebar, keamanan jaringan, pemrograman jaringan, aplikasi mobile untuk bisnis, analisis dan perancangan jaringan, pemrograman web lanjut, sistem layanan berbasis lokasi, infrastruktur layanan mobile, teknologi nirkabel dan aplikasinya, sistem tertanam, serta hal-hal yang berkaitan dengan itu, termasuk di dalamnya aspek perangkat keras komputer.

\section{Al Hadits}

Menurut Terjemahan Riyadus Shalihin. Secara stuktur hadits terdiri atas dua kompomen yaitu sanad atau isnad (rantai rowi) dan matan (redaksi).

1) Sanad atau Isnad

Sanad ialah rantai Rawi atau perawi (periwayat) hadits.Sanad terdiri atas seluruh rawi mulai dari orang yang mencatat hadist tersebut dalam kitab hadist sehingga mencapai Rasulullah. Sanad, memberikan gambaran keaslian suatu riwayat.

2) Klasifikasi Hadit Hadits dapat diklasifikasikan berdasarkan beberapa kritaria yakni bermulanya akhir sanad, keutuhan rantai sanad, jumah rawi (perriwayat) serta tingkat keaslian hadits (dapat diterima tidaknya hadits bersangkutan).

\section{Android}

Android adalah sebuah sistem operasi untuk perangkat mobile berbasis Linux yang mencakup sistem operasi, middleware dan Aplikasi. Android menyediakan platform terbuka bagi pengembang untuk menciptakan aplikasi mereka. Awalnya Google Inc. Membeli Android Inc. Yang merupakan pendatang baru yang membuat piranti lunak untuk ponsel atau smartphone. Kemudian untuk mengembangkan Android, dibentuklah Open Handset Alliance, konsorsium dari dari 34 perusahaan piranti keras, piranti lunak, dan telekomunikasi, termasuk Google, HTC, intel, Motorola, Qualcomm, T - Mobile, dan Invidia.

Pada masa saat ini sebagai besar vendorvendorsmartphone sudah memproduksi smartphone berbasis Android, vendor-vendor itu antara lain HTC, Motorola, Samsung, LG, HKC, 
Huawei, Archos, Webstatoin Camangi, Dell, Nexus, SciPhone, WayteQ, Sony Ericsson, Acer, Philips, T Mobile, Nexian, IMO, Asus dan masih banyak lagi vendor smartphone didunia yang memproduksi Android. Hal ini, Karena Android itu adalah sistem operasi yang open sourse sehingga bebas didistribusikan dan dipakai oleh vendor manapun.

Tidak hanya menjadi sistem operasi dismartphone, saat ini Android menjadi pesaing utama dari Apple pada sitem operasi Table PC. Pesatnya pertumbuhan. Android selain faktor yang disebutkan diatas adalah karena Android itu sendiri adalah platform yang sangat lengkap baik itu sistem operasinya, Aplikasi dan Tool pengembangan, Market aplikasi Android serta dukungan yang sangat tinggi dari komunitas Open Source didunia, sehingga Android terus berkembang pesat baik dari segi teknologi maupun dari segi jumlah device yang ada didunia.

\section{E. UML (Unified Modeling Language)}

UML (Unified Modeling Language) adalah bahasa pemodelan untuk sistem atau perangkat lunak yang berparadigma "berorientasi objek". Pemodelan (modeling) sesungguhnya digunakan untuk penyederhanaan permasalahanpermasalahan yang kompleks sedemikian rupa sehingga lebih mudah dipelajari dan dipahami."

UML (Unified Modeling Language) yang berarti bahasa pemodelan standar [4]. UML dapat diaplikasikan untuk maksud tertentu, biasanya antara lain untuk :

- Merancang perangkat lunak.

- Sarana komunikasi antara perangkat lunak dengan proses bisnis.

- Menjabarkan sistem secara rinci untuk analisa dan mencari apa yang diperlukan sistem.

- Mendokumentasi sistem yang ada, prosesproses dan organisasinya.

Blok pembangun UML adalah diagram. Beberapa diagram ada yang rinci (jenis timing diagram) dan lainnya ada yang bersifat umum (misalnya diagram kelas). Pada pengembang sistem berorientasi objek menggunakan bahasa model untuk menggambarkan, membangun dan mendokumentasikan sistem yang mereka rancang.

\section{ANALISA SISTEM}

Untuk merancang sebuah aplikasi pembelajaran Hadits Riyadhus Shalihin berbasis Android, maka terlebih dahulu perlu dilakukan analisis sebuah sistem pembelajaran Hadits yang sedang berjalan. Penulis menggunakan metedologi berorientasi objek, dengan demikian sebelum membuat sebuah aplikasi hendaknya melakukan analisis terlebih dahulu terhadap kebutuhan- kebutuhan apa aja yang diperlukan dengan menggunakan metode-metode yang telah ada.

Analisa sistem yang sedang berjalan pada sistem pembelajan hadits di Pondok Pesantren Yatim-Dhu'afa Al-Latifah bertujuan untuk lebih jelas bagaimana cara sistem proses pembelajaran tersebut dan masalah yang dihadapi sistem, sehingga dapat dijadikan sebagai landasan usulan perancangan sistem. Maka berikut merupakan sistem yang sedang berjalan :

- Proses pembelajaran dimulai ketika santri dan pengajar didalam kelas.

- Pengajar pada dasarnya memiliki materi dan siap atas materi yang disampaikan kepada santri pada setiap pertemuan.

- Sebagai santri, pada dasarnya mendapat materi dan latihan hapalan untuk memperdalam pemahaman materi yang disampaikan.

Adapun kegiatan yang telah dievaluasi kedalam diagram use case adalah sebagai berikut :

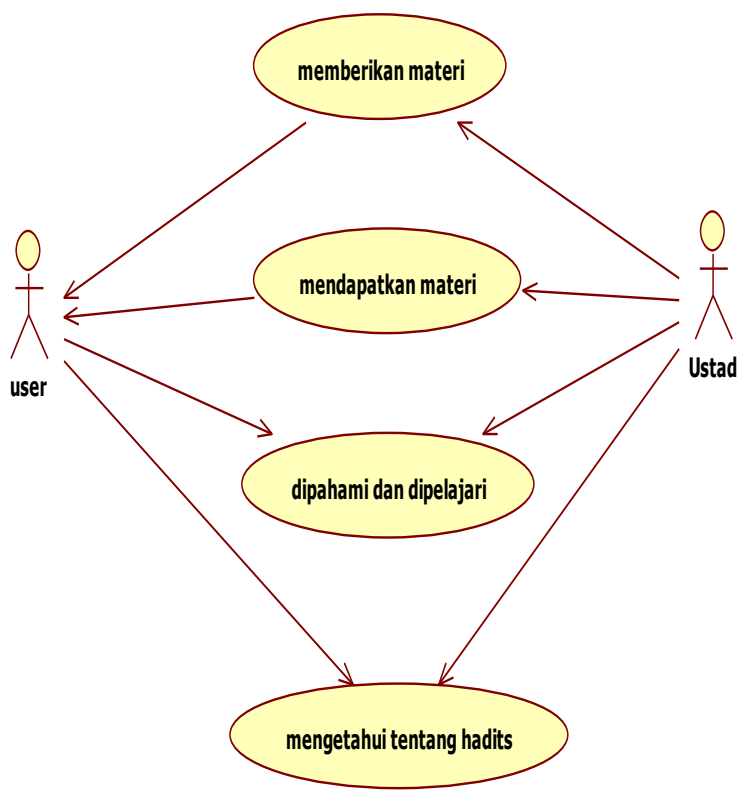

Gambar 1. Use Case Diagram pada sistem yang sedang berjalan

Skenario sistem berjalan pembelajaran

Aktor : Ustad dan Santri

Sekenario : Sistem berjalan pembelajaran

Tabel 1. Sekanario sistem pembelajaran berjalan

\begin{tabular}{|c|c|}
\hline \multicolumn{1}{|c|}{ Ustadz } & Santri \\
\hline $\begin{array}{l}\text { 1. Ustadz memberikan } \\
\text { materi kepada santri }\end{array}$ & \\
\hline & $\begin{array}{l}\text { 2. Santri mendapatkan } \\
\text { materi dari ustadz } \\
\text { dengan pengajaran } \\
\text { langsung. }\end{array}$ \\
\hline
\end{tabular}




\begin{tabular}{|l|l|}
\hline $\begin{array}{l}\text { 3. Materi yang diberikan } \\
\text { dipahami dan dipelajari } \\
\text { oleh ustadz dan santri }\end{array}$ & \\
\hline & $\begin{array}{l}\text { 4. Siswa mengetahui } \\
\text { tentang hadits yang } \\
\text { disampaikan oleh } \\
\text { ustadz }\end{array}$ \\
\hline
\end{tabular}

\section{PERANCANGAN SISTEM}

Gambaran umum dari system yang diusulkan adalah untuk memberikan gambaran secara umum kepada pengguna (user) mengenai sistem aplikasi berbasis Android, perancangan sistem secara umum juga sudah dapat mengenai komponen sistem aplikasi yang akan didesain. Penentuan persyaratan sistem dilakukan agar arah perancangan sistem dapat terarah pada sasaran, oleh sebab itu sistem yang dirancang harus memenuhi batasan sistem. Dimana perancangan sistem aplikasi ini merupakan kebutuhan fungsional. Implementasi menggambarkan bagaimana suatu sistem di bentuk. Pada tahap perancangan aplikasi mobile dirancang dengan tujuan sebagai alat komunikasi antara pemakai (user) dengan pembuat program guna mendapatkan sistem aplikasi yang sesuai dengan apa yang dibutuhkan.

Sistem yang dibangun berbasis android, dengan model UML.Use case diagram adalah diagram yang menyajikan interaksi antara use case dan Actor. Dimana actor dapat berupa orang, peralatan atau sistem lain yang berinteraksi dengan sistem yang sedang dibangun. Use case menggambarkan fungsionalitas sistem atau persyaratan-persyaratan yang harus dipenuhi sistem dari pandangan pemakai. Actor adalah sebuah entitas manusia atau mesin yang berinteraksi dengan sistem untuk melakukan pekerjaanpekerjaan tertentu.

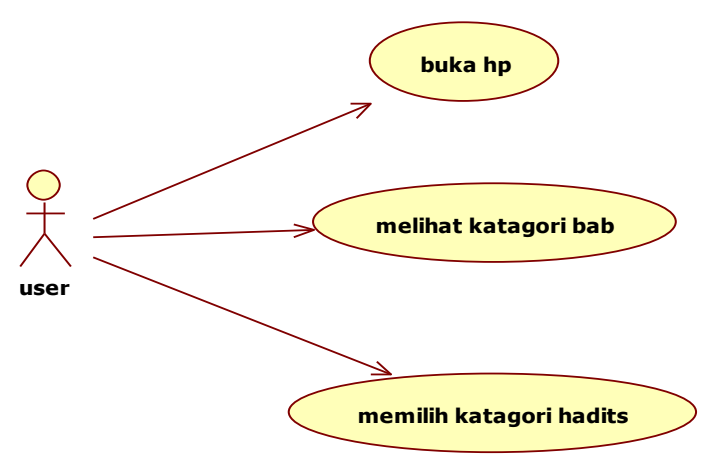

Gambar 2. Use Case penggunaan sistem

1) Skenario Sistem Usulan

Aktor : Santri

Sekenario : Sistem usulan
Tabel 2. Skenario sistem usulan

\begin{tabular}{|ll|l|}
\hline \multicolumn{1}{|c|}{ Santri } & \multicolumn{1}{c|}{ Sistem } \\
\hline $\begin{array}{l}\text { 1. } \\
\text { Santri melihat } \\
\text { materi pada sistem }\end{array}$ & 2. Menampilkan isi materi \\
\hline $\begin{array}{l}\text { 3. } \\
\begin{array}{l}\text { Santri memperlajari } \\
\text { dan memahami } \\
\text { tentang hadits }\end{array}\end{array}$ & \\
\hline
\end{tabular}

Skenario melihat kategori materi pembahasan.

Skenario Sistem Usulan

Aktor : Santri

Sekenario : Melihat kategori materi

pembahasan

Tabel 3

Sekenario Kategori Melihat Materi Pembahasan

\begin{tabular}{|c|c|}
\hline Santri & Aplikasi \\
\hline \multicolumn{2}{|l|}{$\begin{array}{l}\text { 1. Santri memilih menu yang } \\
\text { tersedia didalam sistem }\end{array}$} \\
\hline & $\begin{array}{l}\text { 2. Aplikasi } \\
\text { menampilka } \\
\mathrm{n} \text { kategori } \\
\text { materi } \\
\text { dengan sub } \\
\text { BAB }\end{array}$ \\
\hline \multicolumn{2}{|l|}{$\begin{array}{l}\text { 3. Murid Memilih materi } \\
\text { berdasarkan BAB }\end{array}$} \\
\hline & $\begin{array}{ll}\text { 4. } & \text { Sistem } \\
\text { menampilka } \\
\text { n materi } \\
\text { pembahasan }\end{array}$ \\
\hline
\end{tabular}

\section{IMPLEMENTASI DAN PENGUJIAN SISTEM}

A. Implementasi Sistem

1) Tampilan Menu Utama

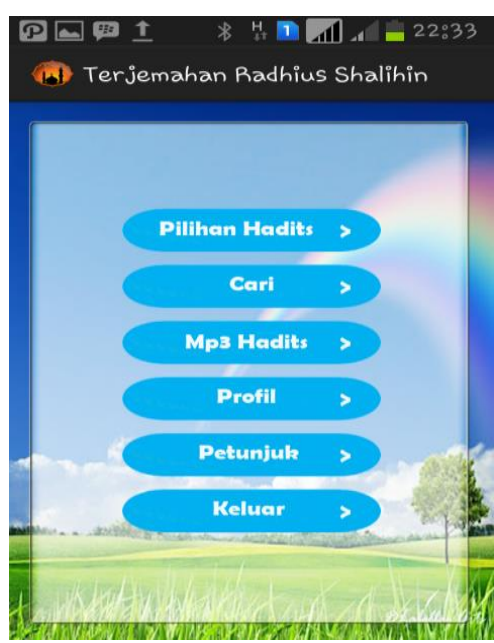

Gambar 3. Tampilan Halamn Utama 
2) Tampilan Menu Pilihan Hadits

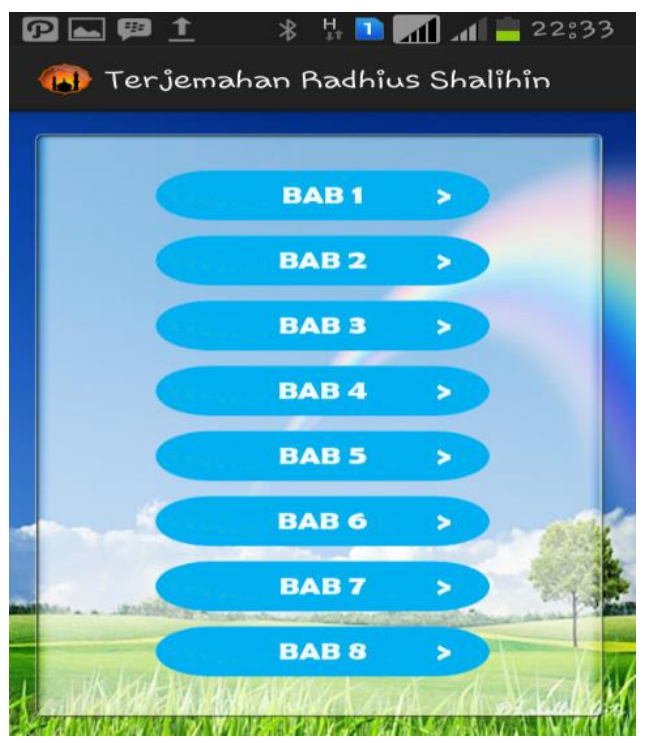

Gambar 4. Tampilan Menu Pilihan Hadits

3) Tampilan di dalam Pilihan Hadits

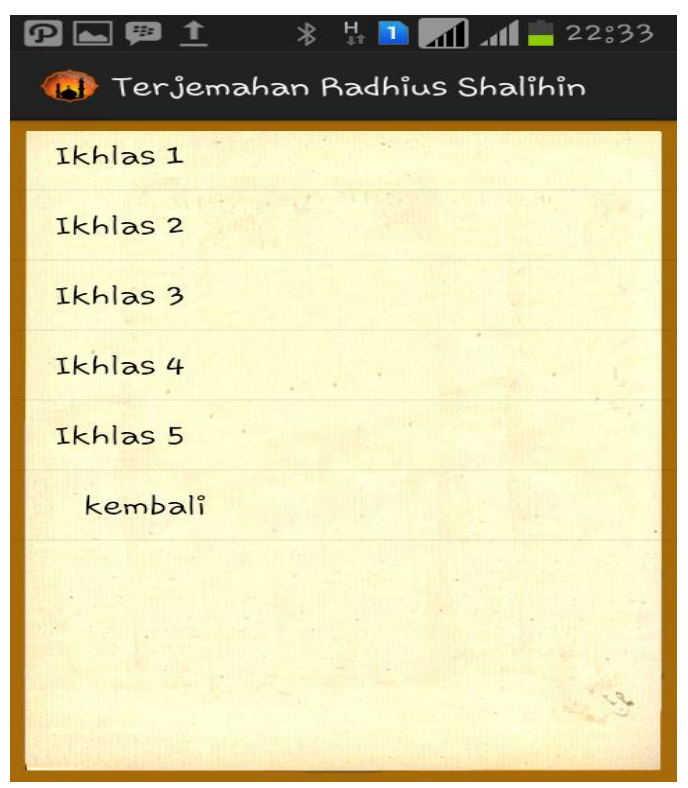

Gambar 5. Tampilan di dalam Pilihan Hadits

\section{B. Pengujian Sistem}

Aplikasi ini berjalan pada perangkat handphone yang bersistem operasi android dengan versi jellybean. Maka dari itu untuk menjalankan aplikasi ini memerlukan handphone android dengan versi jellybean agar tidak terjadi error pada aplikasi tersebut.

1) Perangkat Lunak Yang Digunakan

- Eclipse sebagai perancang program dan desain program.

- Android Virtual Device (AVD) dan Bluestack sebagai menampilan hasil program yang sudah didesain.
2) Perangkat Keras Yang Digunakan Perangkat keras yang digunakan adalah handphone yang mempunyai sistem operasi android.

Cara menjalankan program dengan spesifikasi yang sudah ditentukan adapun langkah-langkahnya sebagai berikut :

- Siapkan handphone dengan sistem operasi android.

- Install aplikasi tersebut dan jalankan program.

C. Kelebihan Dan Kekurangan Program

1) Kelebihan Program

- Mempermudah user untuk belajar Hadits Riyadhus Shalihin.

- Mudah dipelajari.

- Bisa dipakai di sistem operasi android denngan versi tertentu.

2) Kekurangan program

- Aplikasi ini hanya bisa dipakai di sistem operasi android GengerbreadHoneycomb, ICS, jelly bean.

- Tidak bisa dipakai pada sistem operasi lain selain android dengan versi tertentu.

\section{PENUTUP}

A. Kesimpulan

Berdasarkan pembahasan diatas dan pembuatan program yang telah dibuat penulis menyimpulkan sebagai berikut :

- Bahwa sistem pembelajaran Hadits yang manual sekarang ini harus mampu berganti dengan sistem mobile, karena dengan sistem menggunakan media buku dan papan tulis, bisa membuat jenuh.

- Aplikasi ini dibuat untuk memberikan kemudahan kepada pengguna karena dilengkapi dengan pencarian hadits dan mendengarkan hadits.

- Dengan aplikasi ini mampu menunjang proses pengetahuan dan pembelajaran hadits.

\section{B. Saran}

Bedasarkan pembuatan program aplikasi ini masih banyak kekurangan yang harus dikembangkan lagi sehingga bisa meningkatkan program aplikasi tersebut dikemudian hari. Beberapa saran penulis yang harus dikembangkan :

- Pada pengembangan selanjutnya aplikasi ini harus memiliki data base.

- Pada pengembangan selanjutnya harus ditambahkan beberapa hadits tidak terpatok pada hadits pilihan.

- Aplikasi yang sudah dibangun dapat dikembangkan lagi agar menjadi aplikasi 
yang lebih interaktif dan lengkap sehingga dapat digunakan oleh semua kalangan umat muslim.

- Untuk mengenalkan aplikasi ini alangkah baiknya jika dipromosikan secara langsung ataupun online melalui berbagai media.

\section{DAFTAR PUSTAKA}

[1] Nova Nurhuda. 2010. "Membangun Website Indexs Hadist Riyadhus Shalihin Untuk Pengguna Buta Huruf Arab" Jurnal, AMIKOM. Yogyakarta.
[2] Abdul Bari, Rendy Hardi Saputra. 2010, "Penerapan Pencarian Kata Dengan Vector Space Model Pada Aplikasi Terjemah Juz Amma Berbasis Java Me" Jurnal, STMIK Global Informatika Multi Data. Palembang.

[3] Mustika, Damas Rani. 2013, "Pembutan Aplikasi Kitab Fadilah Amal Oleh SyakhulHadits Maulana Muhammad Zakaria Al- Kandahlawi Rah. A Berbasis Android" Jurnal, AMIKOM. Yogyakarta.

[4] Widodo, Pudjo Prabowo. 2010, "Mengenal $U M L$ ” Penerbit Informatika Bandung. 